\title{
Significance of the so-called J-shaped sella in the diagnosis of intracranial aneurysm
}

\author{
M. W. G. WREN \\ United Liverpool Hospitals
}

The purpose of this paper is to draw attention to the importance of recognizing the presence of a J-shaped sella (Fig. I) as an aid in the diagnosis of a slow-growing tumour adjacent to the sella turcica. This formation has not always been regarded as important, because it is sometimes seen in normal persons and particularly in children (Burrows, 1964), but it is known that in cases of optic nerve gliomata, third ventricular dilatation, and in some slowly-growing suprasellar tumours ( $\mathrm{Du}$ Boulay, 1965) there is a high incidence of $\mathrm{J}$-shaped sellae. They are also found in a high percentage of cases of gargoylism, mongolism, cretinism, and achrondroplasia.

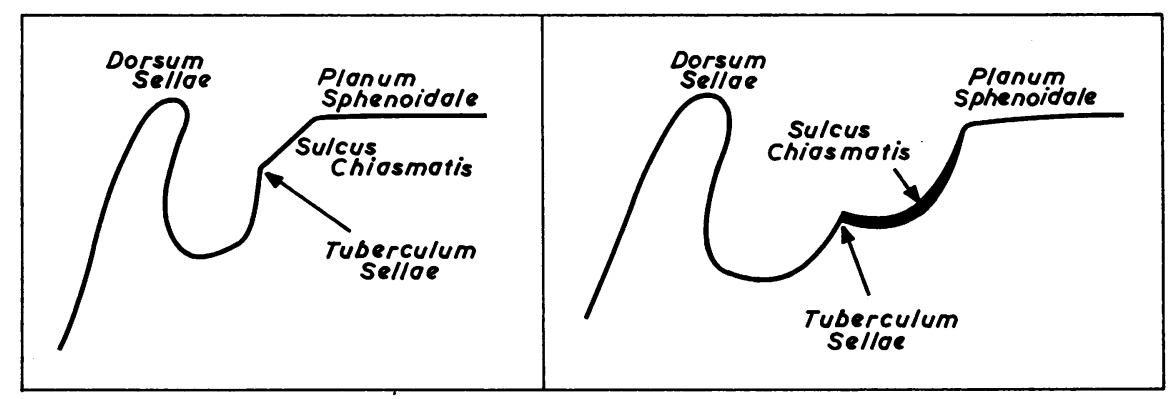

FIG. I Diagram of normal and $\mathbf{Z}$-shaped sellae

The following case illustrates how a diagnosis was obtained by the recognition of this condition.

\section{Case report}

A woman aged 5I years attended the out-patients clinic with a history of inflammation in the left eye one year before. About 6 months later she had noticed that the vision in this eye was deteriorating, and this had continued until the time when she was seen. Her only other symptom was occasional occipital headache for the previous 2 months.

\section{Examination}

There was atrophy of the left optic nerve and the blood pressure was $170 / 105$. Otherwise she was clinically normal. 
A straight $x$ ray of the skull showed a J-shaped sella and the pineal appeared to be central (Figs 2 and $\mathbf{B})$. No pathological intracranial calcification or further abnormality was detected.
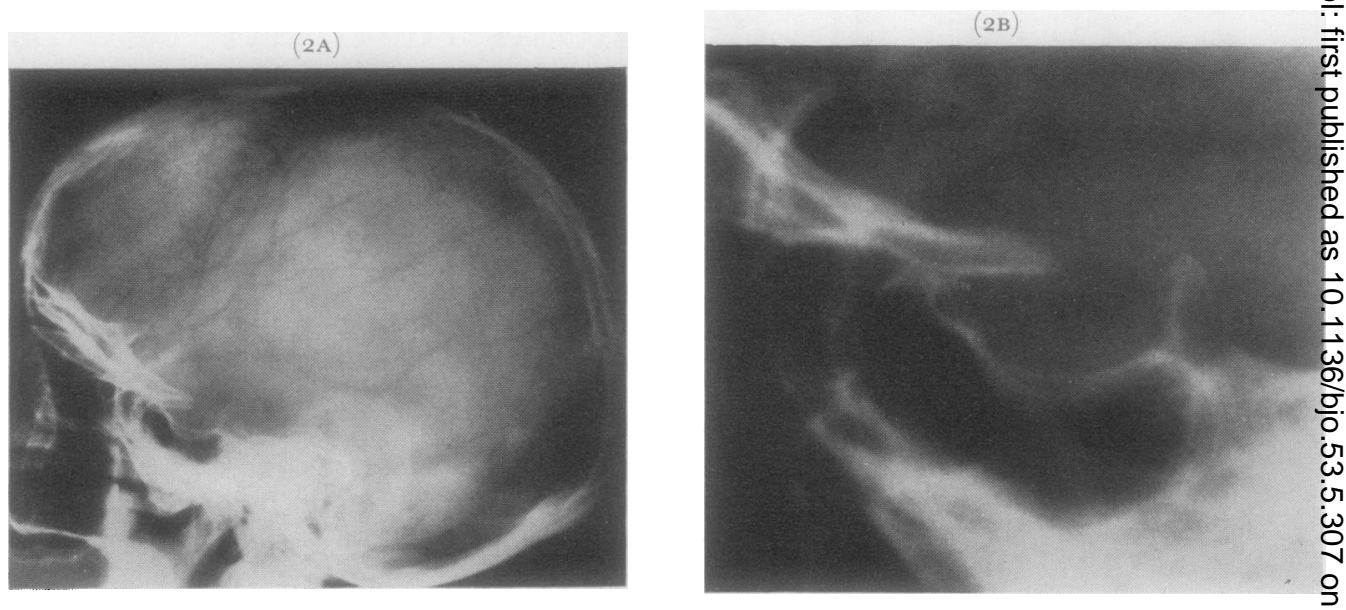

FIG. 2A X ray of skull, showing $\mathcal{J}$-shaped sella, with enlargement (FIG. 2 B)

Because of these findings a tentative diagnosis of optic nerve glioma was made and angiography was suggested. Carotid angiograms (Figs 3 and 4 ) showed a very large aneurysm arising from thog distal portion of the left internal carotid artery just proximal to its bifurcation.
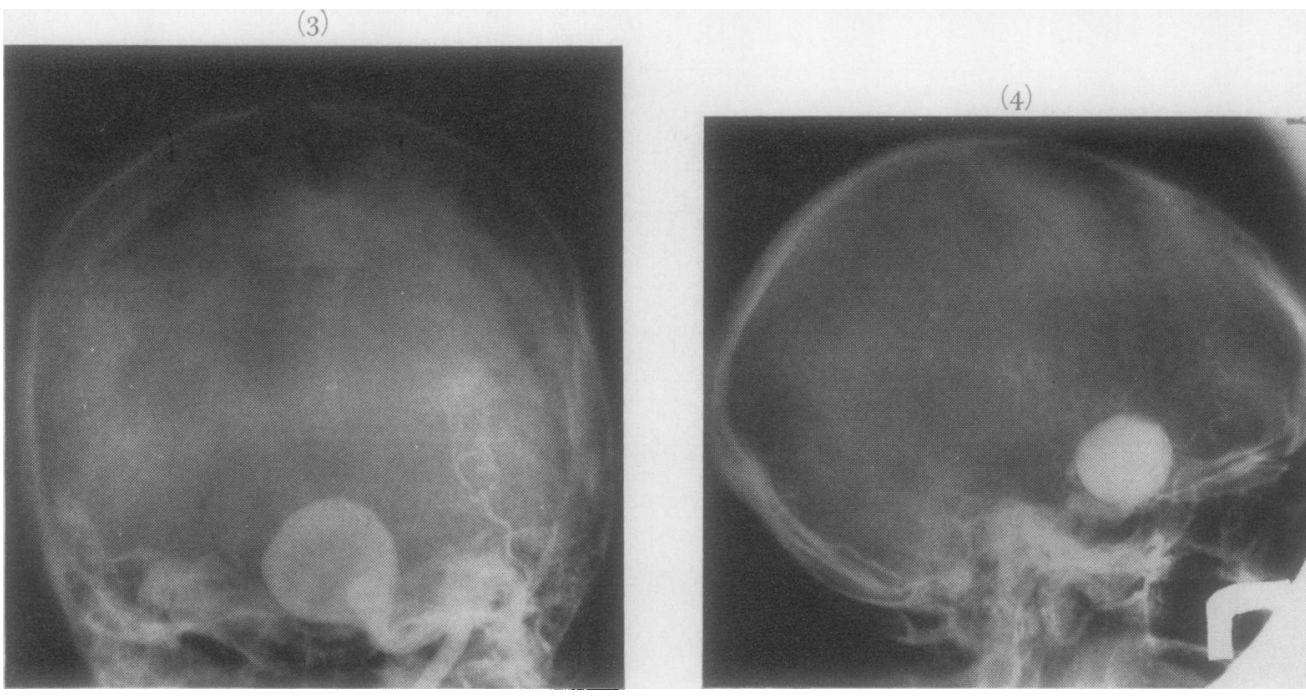

FIGS 3 and 4 Carotid angiograms, showing large aneurysm

The patient was then referred for a neurosurgical opinion, but it was felt that a carotid arter ligation would be unsatisfactory, partly because of the size of the aneurysm and partly because of the risk of ensuing hemiparesis.

\section{Discussion}

Martin and Cushing (1923) first described a peculiar radiological appearance of the pituitary fossa frequently present in cases of optic nerve gliomata. Several descriptive 
names have been given to this phenomenon; the Americans call it the "J-shaped sella" and the French and Germans have described it as being of an "omega" or "hour-glass" shape. The J-shaped sella is seen on the lateral view of the skull as a forward extension of the pituitary fossa beneath the anterior clinoid processes. This extension of the anterior aspect of the sella is distinguished from the true pituitary fossa by a small elevation representing the tuberculum sellae. The extension may resemble a mirror image of the pituitary fossa itself.

On the lateral view of a normal skull, the superior surface of the sphenoid bone in the mid-line shows three distinct areas: the planum sphenoidale, the sulcus chiasmatis, and the pituitary fossa.

In cases showing the J-shaped sella there is a depression and hollowing of the sulcus chiasmatis, and the cortex of the floor of the sulcus usually remains intact. The deficiency of this region may be explained either by pressure due to a local tumour or by poor development and remodelling as in congenital or hereditary cases. J-shaped sellae have been found in 5 per cent. of normal children, but when these regions were re-examined in later life they were found to have become normal. These findings were put down to the normal growth process of the sphenoid bone, and the presence of a J-shaped sella in a child is thus of little importance. Taveras and Wood (1964) stated that, in the absence of gargoylism and hydrocephalus and also in the very young, a J-shaped sella should always be regarded as abnormal until another explanation can be found.

\section{References}

BURRows, E. H. (1964) Brit. F. Radiol., 37, 66 I

DU boulay, G. H. (1965) "Principles of X-ray Diagnosis of the Skull". Butterworths, London martin, P., and cushing, H. (1923) Arch. Ophthal., 52, 209

TAVERAS, J. M., and wood, E. H. (1964) "Diagnostic Neuroradiology". Williams and Wilkins, Baltimore 